\begin{tabular}{|c|c|c|}
\hline \multirow{2}{*}{$\begin{array}{r}\text { Case Reports in } \\
\text { Gastroenterology }\end{array}$} & \multicolumn{2}{|c|}{ Case Rep Gastroenterol 2016;10:531-537 } \\
\hline & $\begin{array}{l}\text { DOI: 10.1159/000448885 } \\
\text { Publisnea onine:. Uctover 10, } 2016\end{array}$ & $\begin{array}{l}\text { (c) } 2016 \text { The Author(s) } \\
\text { Published by S. Karger AG, Basel } \\
\text { www.karger.com/crg }\end{array}$ \\
\hline & \multicolumn{2}{|c|}{$\begin{array}{l}\text { This article is licensed under the Creative Commons Attribution-NonCommercial } 4.0 \\
\text { International License (CC BY-NC) (http://www.karger.com/Services/OpenAccessLicense). } \\
\text { Usage and distribution for commercial purposes requires written permission. }\end{array}$} \\
\hline
\end{tabular}

\title{
Cirrhotic Cardiomyopathy: Another Case of a Successful Approach to Treatment of Hepatorenal Syndrome
}

\author{
Luis Otávio Mocarzel $^{\mathrm{a}}$ Jessica Bicca ${ }^{\mathrm{a}} \quad$ Luiza Jarske $^{\mathrm{a}} \quad$ Thamires Oliveira $^{\mathrm{a}}$ \\ Pedro Lanzieri $^{a} \quad$ Ronaldo Gismondi $^{a}$ Mario Luiz Ribeiro ${ }^{b}$ \\ ${ }^{a}$ Department of Internal Medicine, Hospital Universitário Antônio Pedro, Universidade \\ Federal Fluminense, Niterói, Brazil; ${ }^{b}$ Department of Cardiology, Hospital Universitário \\ Antônio Pedro (HUAP), Niterói, Brazil
}

\section{Keywords}

Cirrhotic cardiomyopathy - Left ventricular diastolic dysfunction · Heart failure $\cdot$ Hepatic insufficiency · Cirrhosis · Hepatorenal syndrome

\begin{abstract}
Hepatorenal syndrome (HRS) is defined as a failure of renal function, potentially reversible, in patients with liver cirrhosis and ascites. Recently, a component of cardiomyopathy associated with HRS was described, but the use of positive inotropic medicine as part of the treatment of the acute phase has not been extensively evaluated. We report a second case in our hospital of a patient with HRS type I without previous heart disease, with secondary hemodynamic decompensation due to liver disease, in which the abnormalities in systolic function by speckle-tracking echocardiography were observed and could be reversed by the use of inotropes. After partial response to current therapies, the patient presented a clinical and laboratorial response with improvement of renal function after infusion of dobutamine. Clinical studies are needed for the therapy approach to HRS taking into account myocardial dysfunction as a major contributing factor for renal dysfunction.

(C) 2016 The Author(s)

Published by S. Karger AG, Basel
\end{abstract}




\section{Introduction}

Cirrhosis is defined as the final stage of chronic liver disease, characterized by modifications in hepatic parenchyma with fibrosis and regeneration nodes [1, 2]. Most of the cases are associated with hepatitis $\mathrm{B}$, hepatitis $\mathrm{C}$ and alcoholic hepatitis, in addition to cryptogenic cirrhosis $[3,4]$. Extensive hepatic fibrosis leads to an increase in portal pressure and to portosystemic shunt, associating with peripheral vasodilatation and hyperdynamic circulation. Some systemic repercussions may be consequent of these impairments, with multiple organ dysfunction, such as cirrhotic cardiomyopathy (CCM) and hepatorenal syndrome (HRS) [2, 4, 5].

HRS is characterized by deterioration of renal function in severe hepatic cirrhotic patients. Its pathological mechanism involves renal vasoconstriction secondary to activation of the renin-angiotensin-aldosterone system, hyperdynamic circulation and CCM [6-8]. Recently, an association between CCM and HRS has been described, suggesting that CCM may be the main determinant of renal dysfunction in advanced cirrhotic patients [2]. While most of the established treatments of HRS rely on vasoconstrictors and improvement of oncotic pressure with albumin, little attention has been given to the associated cardiac dysfunction.

Hepatic cirrhosis may have a set of clinical presentations including both CCM and HRS. These clinical conditions might be related to each other and, since most of the patients remain asymptomatic for a long time - due to reduced vascular peripheral resistance and compensative increase in cardiac output - it may only present clinically in a stressing scenario $[5,9]$. On the other hand, CCM is characterized by a decrease in ventricular response to stress even though the patient presents normal or increased basal cardiac output. Systolic, diastolic, electrophysiological, structural, histological and biochemical modifications are noticed in CCM [10-13].

We report a case of a patient with HRS type I refractory to usual protocols [6], with high levels of propeptide of brain natriuretic peptide but with normal left ventricle ejection fraction and impaired systolic global strain on echocardiogram. Subclinical cardiac dysfunction proved to be reversible by the infusion of dobutamine as rescue therapy, leading to a renal dysfunction regression within days.

\section{Case Report}

A 46-year-old Afro-descendant Brazilian woman presents a history of cryptogenic hepatic cirrhosis diagnosed 1 year previously. Since that time, she was on propranolol $20 \mathrm{mg}$ t.i.d., spironolactone $100 \mathrm{mg}$ s.i.d., and furosemide $40 \mathrm{mg}$ s.i.d. Her previous pathological history did not include any hospitalization due to decompensated cirrhosis or cardiopathy.

She was admitted to the emergency room with a 3-week history of worsened anasarca, postprandial fullness, jaundice and acholic feces. Her physical exam was relevant for a blood pressure of $100 / 80 \mathrm{~mm} \mathrm{Hg}$, heart rate of 110 beats and respiratory rate of 18 breaths per minute. There were clinical signs of malnutrition, pallor, and voluminous ascites. Cardiovascular evaluation and jugular venous pressure were normal.

Upon admission, she was classified as Child C14 and MELD 26. Chest X-ray showed bilateral pleural effusion and normal cardiac area. Electrocardiogram revealed a sinus rhythm with normal wave morphology and corrected QT interval (QTc) of $390 \mathrm{~ms}$ for Bazett's formula. Echo Doppler cardiogram showed otherwise normal ejection fraction (Simpson's) and normal cavity diameters, and an impairment in segmental peak-systolic longitudinal strain 
(fig. 1a), in comparison with the following day (fig. 1b, c). Upper digestive endoscopy was positive for four varicose cords of $6-10 \mathrm{~mm}$, and varicose veins with red color spots. Abdomen ultrasonography was positive for hepatic heterogeneous echotexture and sparse solid nodes in parenchyma. Cholangiography indicated a reduction in liver size with irregular margins, a heterogeneous parenchyma, and the presence of nodules with contrast enhancement in the arterial phase (major with $5.2 \times 4.8 \times 0.8 \mathrm{~cm}$ ), suggestive of hepatocellular carcinoma. Laboratory tests are described in table 1.

Due to abdominal symptoms and tense ascites, she was submitted to paracentesis, which was diagnostic of spontaneous bacterial peritonitis (SBP) with fluid protein of 2.5 $\mathrm{g} / \mathrm{dl}$. Treatment with antibiotics and albumin was started according to the protocol established by the American Association for the Study of Liver Diseases [14].

The patient showed progressive improvement of infectious parameters. However, hepatic encephalopathy was noticed and treated with metronidazole and lactulone, besides a clinical course of HRS type I, characterized by progressive worsening of renal function, as evidenced by oliguria and increase of creatinine. Treatment was based on albumin and octreotide administration, following HRS protocols [7]. Nevertheless, the patient evolved to anuria and azotemia. Given this unfavorable scenario, dobutamine was introduced as a rescue therapy. There was progressive improvement of renal function, increased urine output and reduction of creatinine in the following days (fig. 2). Treatment with dobutamine lasted 4 days.

Upon discontinuation of inotropic medication, renal function recovered and remained stable. The patient was discharged 7 days after the intervention.

\section{Discussion}

This report shows a cirrhotic patient with no previous history of heart disease who presented with HRS type I in the context of SBP. Despite standard treatment with albumin and vasopressors, the patient developed oliguria, which only improved after dobutamine infusion.

The circulation's hyperdynamic status, to which the cirrhotic patient is subjected, due to the high concentration of vasodilators in circulation and consequent sympathetic hyperactivation, reduces cardiac reserve, whereas the myocardium is under maximum demand in normal conditions. Situations that require increased cardiac performance, as SBP or other high cardiac output conditions, may decompensate cardiac function in cirrhotic patients. Those patients may also present chronotropic and inotropic dysfunction due to impairment of beta-adrenergic receptors and disorders of the calcium signaling pathway. These changes contribute to a disturbance in myocardial contractility, at the expense of contractile force and heart rate [10]. Due to cardiac fatigue, the patient evolves with systolic failure and low perfusion of organs such as the kidney, which contributes to the appearance of HRS $[7,13]$.

HRS is characterized by an increase in serum creatinine in patients with advanced liver disease and is usually associated with poor prognosis. This may be the final process of evolution of the pathophysiology of liver disease with reduced renal blood flow and glomerular filtration, renal vasoconstriction by activation of the renin angiotensin aldosterone, cardiac dysfunction of cirrhosis, increased circulation of cytokines and vasoactive substances that affect blood circulation [15].

The baseline treatment of HRS relies on the improvement of liver function by correction of the causal factor. Furthermore, specific therapy is required for the circulatory disorder, 
usually with intravenous albumin on the first and third days of treatment, associated with vasopressin or norepinephrine in continuous infusion. Patients with clinical instability may be candidates to terlipressin associated with albumin; the association of octreotide and midodrine is an alternative $[6,16-18]$.

Studies with dopamine in cirrhotic patients demonstrated vasodilation of renal vessels and improvement of renal perfusion, but with no improvement in the parameters of renal function $[16,19]$. Clinical trials comparing standard therapy with terlipressin and albumin with triple therapy of dopamine, albumin and furosemide showed similar results with these approaches [19, 20].

The use of inotropes such as dobutamine and isoproline are not yet validated in patients presenting with CCM, based on studies that demonstrated changes in adrenergic response to isoproline and dobutamine in cirrhotic patients [21, 22]. However, it is not clear if those drug classes could be useful for treating refractory patients on standard therapies, including the action in beta-adrenergic receptors, which increases inotropic response and improves cardiac function. Although cirrhotic patients have impaired beta-adrenergic receptors, an improvement in cardiac output may be observed [22], which may explain the positive effect of dobutamine in patients with HRS.

Treatment with dobutamine has already been described in a similar case report, but with other etiology of liver cirrhosis [23]. The cited case described a white male patient with alcoholic cirrhosis infected with hepatitis $\mathrm{C}$ virus. Because that patient was also refractory to standard therapy for HRS, dobutamine infusion was helpful reverting renal impairment [23]. In this case, the patient had advanced cryptogenic cirrhosis, with higher Child and MELD scores. Based on evidence of the pathophysiological relation between CCM and HRS, and previous experience in our hospital, we started dobutamine. The patient developed sustained improvement in renal function. Our results reinforce the association between CCM and HRS and support the need of more clinical trials on the therapeutic approach with inotropic agents in HRS.

\section{Summary}

We report another case of a patient with HRS type I refractory to usual protocols, with high levels of natriuretic propeptide but with normal left ventricle ejection fraction on echocardiogram. Subclinical cardiac dysfunction proved to be reversible by the infusion of dobutamine as rescue therapy, leading to renal dysfunction regression within days. A previous case report of a cirrhotic patient of another etiology showed success with this approach.

\section{Statement of Ethics}

We obtained informed consent under institutional review board-approved protocols.

\section{Disclosure Statement}

The authors declare that there is no conflict of interests regarding the publication of this paper. 
Mocarzel et al.: Cirrhotic Cardiomyopathy: Another Case of a Successful Approach to Treatment of Hepatorenal Syndrome

\section{References}

1 Schuppan D, Afdhal NH: Liver cirrhosis. Lancet 2008;371:838-851.

-2 Møller S, Henriksen JH, Bendtsen F: Extrahepatic complications to cirrhosis and portal hypertension: haemodynamic and homeostatic aspects. World J Gastroenterol 2014;20:15499-15517.

3 Zhou W-C, Zhang Q-B, Qiao L: Pathogenesis of liver cirrhosis. World J Gastroenterol 2014;20:73127324.

4 Martínez-Esparza M, Tristán-Manzano M, Ruiz-Alcaraz AJ, García-Peñarrubia P: Inflammatory status in human hepatic cirrhosis. World J Gastroenterol 2015;21:11522-11541.

5 Møller S, Bendtsen F: Cirrhotic multiorgan syndrome. Dig Dis Sci 2015;60:3209-3225.

6 Nadim MK, Kellum JA, Davenport A, Wong F, Davis C, Pannu N, et al: Hepatorenal syndrome: the 8th International Consensus Conference of the Acute Dialysis Quality Initiative (ADQI) Group. Crit Care 2012;16:R23.

7 Ruiz-del-Arbol L, Monescillo A, Arocena C, Valer P, Ginès P, Moreira V, et al: Circulatory function and hepatorenal syndrome in cirrhosis. Hepatology 2005;42:439-447.

-8 Baraldi O, Valentini C, Donati G, Comai G, Cuna V, Capelli I, et al: Hepatorenal syndrome: update on diagnosis and treatment. World J Nephrol 2015;4:511-520.

-9 Kim MY, Baik SK, Won CS, Park HJ, Jeon HK, Hong HI, et al: Dobutamine stress echocardiography for evaluating cirrhotic cardiomyopathy in liver cirrhosis. Korean J Hepatol 2010;16:376-382.

10 Gassanov N, Caglayan E, Semmo N, Massenkeil G, Er F: Cirrhotic cardiomyopathy: a cardiologist's perspective. World J Gastroenterol 2014;20:15492-15498.

$\checkmark 11$ Chayanupatkul M, Liangpunsakul S: Cirrhotic cardiomyopathy: review of pathophysiology and treatment. Hepatol Int 2014;8:308-315.

-12 Mota VG, Markman Filho B: Echocardiography in chronic liver disease: systematic review. Arq Bras Cardiol 2013;100:376-385.

-13 Yang Y-Y, Lin H-C: The heart: pathophysiology and clinical implications of cirrhotic cardiomyopathy. J Chin Med Assoc 2012;75:619-623.

14 Runyon BA: Management of Adult Patients with Ascites due to Cirrhosis: Update 2012. Alexandria, American Association for the Study of Liver Diseases, 2012.

15 Arroyo V, Fernández J: Management of hepatorenal syndrome in patients with cirrhosis. Nat Rev Nephrol 2011;7:517-526.

16 Pericleous M, Sarnowski A, Moore A, Fijten R, Zaman M: The clinical management of abdominal ascites, spontaneous bacterial peritonitis and hepatorenal syndrome: a review of current guidelines and recommendations. Eur J Gastroenterol Hepatol 2016;28:e10-e18.

17 Salerno F, Gerbes A, Ginès P, Wong F, Arroyo V: Diagnosis, prevention and treatment of hepatorenal syndrome in cirrhosis. Gut 2007;56:1310-1318.

18 Arroyo V, Terra C, Ginès P: Advances in the pathogenesis and treatment of type- 1 and type-2 hepatorenal syndrome. J Hepatol 2007;46:935-946.

19 Wong F, Pantea L, Sniderman K: Midodrine, octreotide, albumin, and TIPS in selected patients with cirrhosis and type 1 hepatorenal syndrome. Hepatology 2004;40:55-64.

20 Srivastava S, Vishnubhatla S, Prakash S, Sharma H, Thakur B, Acharya SK: Randomized controlled trial comparing the efficacy of terlipressin and albumin with a combination of concurrent dopamine, furosemide, and albumin in hepatorenal syndrome. J Clin Exp Hepatol 2015;5:276-285. Baik SK, Fouad TR, Lee SS: Cirrhotic cardiomyopathy. Orphanet J Rare Dis 2007;2:15.

-22 Mikulic E, Muñoz C, Puntoni LE, Lebrec D: Hemodynamic effects of dobutamine in patients with alcoholic cirrhosis. Clin Pharmacol Ther 1983;34:56-59.

23 Mocarzel L, Lanzieri P, Nascimento J, Peixoto C, Ribeiro M, Mesquita E: Hepatorenal syndrome with cirrhotic cardiomyopathy: case report and literature review. Case Reports Hepatol 2015;2015:573513. 


\section{Case Reports in Gastroenterology}

\begin{tabular}{l|l}
\hline Case Rep Gastroenterol 2016;10:531-537 \\
\hline DOI: 10.1159/000448885 & $\begin{array}{l}\text { C 2016 The Author(s). Published by S. Karger AG, Basel } \\
\text { www.karger.com/crg }\end{array}$ \\
\hline
\end{tabular}

Mocarzel et al.: Cirrhotic Cardiomyopathy: Another Case of a Successful Approach to Treatment of Hepatorenal Syndrome
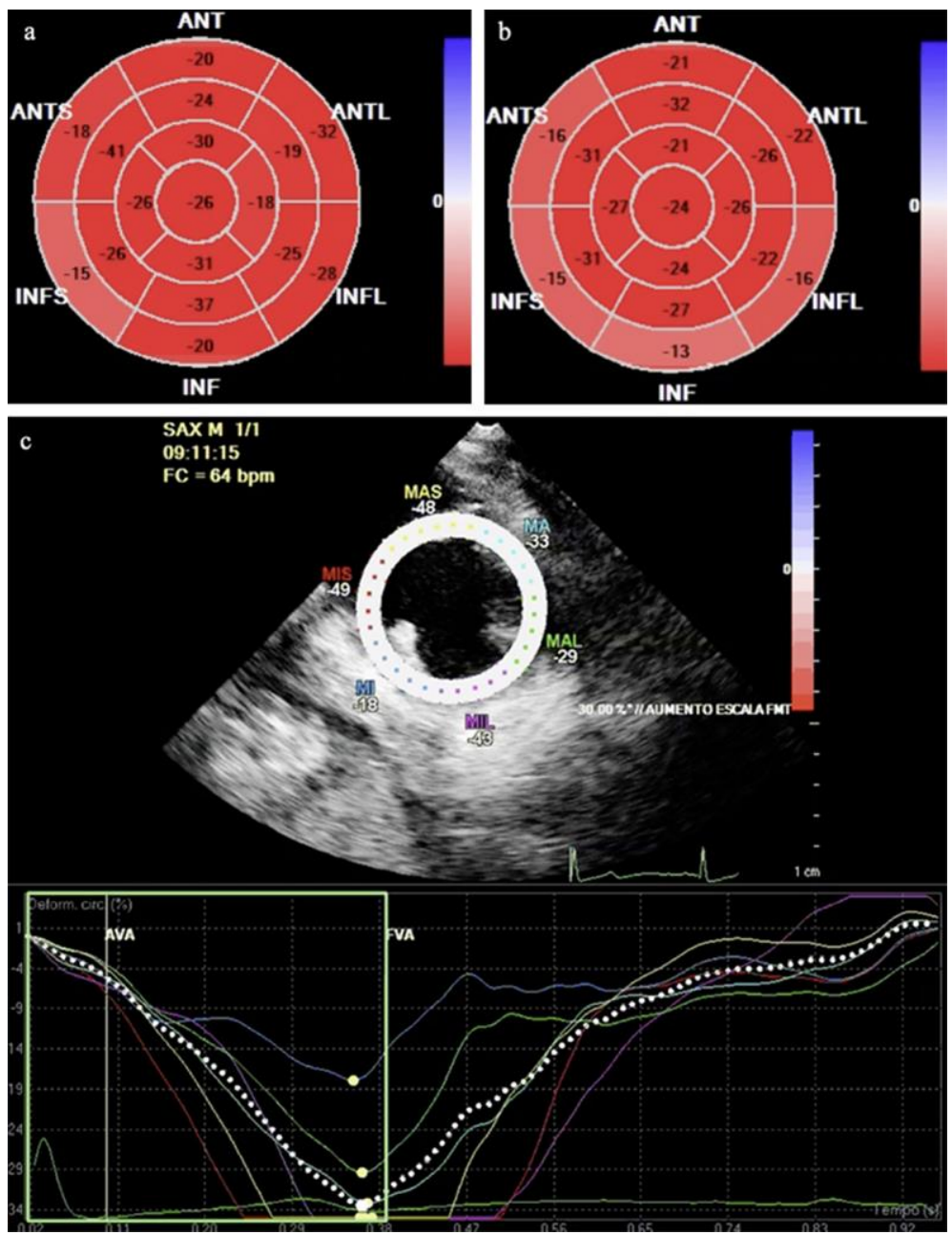

Fig. 1. Bull's eye display of segmental peak-systolic longitudinal strain showing improvement with dobutamine, inferred by systolic global longitudinal strain and systolic global circumferential strain. First evaluation showed values of -20 and $-33 \%$, respectively (a), followed by -23 and $-37 \%$, respectively, on the next day (b). c Longitudinal strain during dobutamine infusion. 


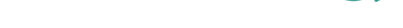

Mocarzel et al.: Cirrhotic Cardiomyopathy: Another Case of a Successful Approach to Treatment of Hepatorenal Syndrome

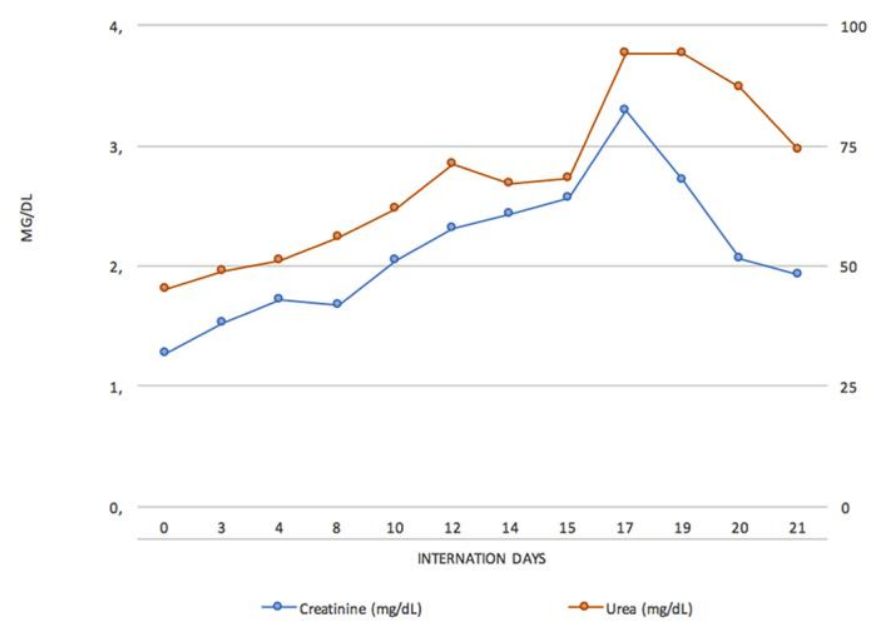

Fig. 2. Urea and creatinine curves during hospitalization. Dobutamine was started on day 14, followed by a progressive decrease in urea and creatinine levels.

Table 1. Laboratory results on admission

\begin{tabular}{lc}
\hline Laboratory tests & Results* \\
\hline Hemoglobin, g/dl & $7.4(12-16)$ \\
Urea, mg/dl & $45(15-45)$ \\
Platelets, $\times 10^{3} / \mathrm{mm}^{3}$ & $117(150-400)$ \\
Leukocytes, $\times 10^{3} / \mathrm{mm}^{3}$ & $11.3(4.5-10.5)$ \\
Creatinine, $\mathrm{mg} / \mathrm{dl}$ & $1.27(0.6-1)$ \\
Total proteins, g/dl & $6.5(6.4-8.2)$ \\
Albumin, g/dl & $1.2(3.4-5)$ \\
AST, U/l & $499(15-37)$ \\
ALT, U/l & $137(15-59)$ \\
GGT, U/l & $147(5-55)$ \\
Total bilirubin, mg/dl & $13.61(\leq 1)$ \\
Conjugated bilirubin, mg/dl & $11.19(\leq 0.3)$ \\
Sodium, mEq/l & $126(136-145)$ \\
Potassium, mEq/l & $4.8(3.5-5.1)$ \\
AFP, U/l & $515(<35)$ \\
\hline
\end{tabular}

AST = Aspartate aminotransferase; ALT = alanine aminotransferase; GGT = gamma-glutamyl transferase; $\mathrm{AFP}=$ alpha-fetoprotein .

* Laboratory reference values are in parentheses. 